\title{
Sociedade do conhecimento e ciência administrativa: reflexões iniciais sobre a gestão do conhecimento e suas implicações organizacionais
}

Alexandre Shigunov Neto

Administrador formado pela Universiddade Estadual de Maringá (UEM): Especialista em Economia Empresarial pela Universidade Estadual de Londrina (UEL); Mestre em Educação pelo Programa de Pós-Graduação em Educação da UEM; Doutorando do Programa de Pós-Graduação em Engenharia e Gestão do Conhecimento (ECC) da Universidade Federal de Santa Catarina (UFSC).

Alexandre Andrade Teixeira

Economista formado pela Universiddade Federal do Paraná (UFPR)

Mestre em Engenharia da Producão pela Universidade Federal de Santa Catarina (UFSC); Professor dos Cursos de Administração e Sistemas de

Informação da Faculdade Cenecista Presidente.

Apresenta algumas reflexões iniciais sobre o papel da gestão do conhecimento e suas implicações organizacionais. Na sociedade capitalista a vantagem competitiva é determinante para o sucesso, até mesmo para a sobrevivência das organizações, principalmente para aquelas com fins lucrativos. Neste contexto, o conhecimento está se tornando o principal fator de produção, elemento determinante da vantagem competitiva das empresas. Todos os competidores têm acesso aos demais fatores de produção, mas o que distingue uma empresa de outra é o conhecimento que cada uma detêm. Aquela que consegue gerir melhor o conhecimento dos seus empregados, de forma a traduzi-lo em produtos e serviços valorizados pela sociedade do consumo, terá uma vantagem competitiva. Considerando-se a importância do conhecimento como fator de produção distintivo na empresa e a necessidade de se obter melhor aproveitamento para efetivação dos objetivos estratégicos das organizações, propõe-se que o conhecimento nas organizações seja gerido de forma consciente e segundo sua contribuição para as competências essenciais e/ou para a visão estratégica da organização. Inclui alguns instrumentos que podem ser utilizados pela empresa para definir critérios de seleção e para estimular a geração de conhecimentos e a inserção da gestão do conhecimento na cultura organizacional.

Palavras-chave: Conhecimento; Ciência administrativa; Sociedade do conhecimento; Organizações 


\section{Considerações iniciais}

A sociedade está vivenciando um período de grandes transformações que afetam diretamente as organizações. Estas transformações, que ocorrem em todos os setores da sociedade, notadamente na economia, têm impacto direto sobre o mundo que cerca o ser humano. Nesse sentido, a contemporaneidade apresenta o conhecimento como o propulsor dessas transformações, ora como vilão, ora como redentor, e pela importância que o mesmo têm adquirido para as organizações, principalmente nas últimas décadas. Pode-se supor que tal importância adquirida pelo conhecimento devese exclusivamente à influência que o modo de produção e distribuição capitalista exerce em nossa sociedade, pautada nos princípios da lucratividade e da concentração de renda.

Na medida em que possui uma ampla capacidade de intervenção na realidade, o conhecimento moderno torna-se um poderoso instrumento para inovar e transformar. O conhecimento produzido em nossa sociedade, também denominado de conhecimento moderno, é um diferenciador entre as nações na sociedade pós-industrial, tornando-se evidente para todos que ele é o principal fator de distinção da capacidade de produção dos países e determinante para o desenvolvimento.

Enquanto aparelho ideológico e instrumento de dominação e poder, o conhecimento moderno pode contribuir para o aumento significativo da exclusão social e da pobreza. Entre alguns dos motivos para que a junção entre o conhecimento moderno e o projeto hegemônico neoliberal obtivesse êxito encontra-se no fato do lucro depender cada vez mais da elaboração de produtos com alto valor agregado, que requer o uso intensivo de conhecimento inovador. Portanto, há estreita relação entre o conhecimento moderno, a inovação e o lucro. Faz-se necessário lembrar que, como normalmente acontece, conhecimento não pode ser confundido com habilidade e aptidão; aquele se refere ao processo de aprendizagem de algo, enquanto que estes se referem aos conhecimentos técnicos, estando correlacionados a alguma profissão. Na medida em que o conhecimento passa a ser considerado o bem mais importante dos homens, pressupõe-se que seja, também, fator determinante para o sucesso profissional dos empregados e das organizações. Assim, pretende-se demonstrar as implicações organizacionais da gestão do conhecimento e como o seu adequado gerenciamento pode ser transformado em vantagem competitiva, segundo o conceito de core competence de Hamel e Prahalad. Objetiva-se, portanto, discutir o impacto do conhecimento nas organizações e sugerir alguns instrumentos administrativos para a organização se estruturar para responder, de forma adequada e vantajosa, aos desafios do meio ambiente.

\section{Neoliberalismo e a sociedade do conhecimento}

A partir de 1970, com a crise do Estado do Bem-Estar Social e sua incapacidade para resolver os graves problemas econômicos, as propostas neoliberais ressurgem com força total e difundem-se como a única solução possível para a economia mundial sair da crise que havia se instaurado. 
Alguns dos motivos do grande impulso tomado pela ideologia neoliberal foram: a crise dos anos 70, a incapacidade do Estado de Bem-Estar Social em resolver os graves problemas econômicos gerados pela crise, e a consagração de Frederick Hayek e Milton Friedman, que receberam, respectivamente em 1974 e 1976, o Prêmio Nobel de Economia. Nesse sentido, havia no mundo, nessa época, um clima ideológico, político e social propício para a implantação do neoliberalismo (SHIGUNOV NETO e MACIEL, 2004).

primeiro governo a adotar explicitamente as propostas neoliberais como um programa de governo foi o de Margaret Tatcher, em 1979, na Inglaterra, seguido pelos Estados Unidos (Ronald Reagan), em 1980, e na Alemanha, pelo governo do Primeiro-ministro Helmut Kohl (em 1982). Entretanto, não demorou muito para que a retórica neoliberal se expandisse para os demais países europeus, para o Leste Europeu e, posteriormente, para a América Latina. Dessa forma, teve início o processo de construção hegemônica. Na América Latina a ideologia neoliberal foi amplamente difundida, alastrando-se por uma grande quantidade de países. No caso específico do Brasil, o maior exemplo de programas neoliberais encontram-se na administração de Fernando Henrique Cardoso, ao implementar alguns projetos, dentre os quais destacam-se: Programa Avança Brasil, os programas de privatizações de empresas públicas, o de Bolsa Alimentação, o de Bolsa Escola, o da Sociedade da Informação. No âmbito da iniciativa privada encontram-se também projetos de caráter neoliberal, como o Projeto Educacional Amigos da Escola, que é uma iniciativa da Rede Globo de Televisão, que o desenvolve juntamente com o Projeto Brasil 500 Anos e o Comunidade Solidária, que destina-se a fortalecer a participação comunitária no esforço de melhoria da escola pública.

A hegemonia neoliberal obteve êxito parcial ao atingir seus objetivos secundários: houve deflação, aumento dos lucros industriais, aumento das taxas de desemprego e baixa dos salários dos trabalhadores. Entretanto, o objetivo último, a reanimação do capitalismo avançado mundial, não foi atingida, pois não se verificou expansão das taxas de crescimento econômico. Na medida em que a crise econômica se agravava, a ideologia neoliberal se alastrava pelo mundo capitalista e se (re)afirmava como sendo a única solução possível para todos os problemas da sociedade. Sustentavam os neoliberais que não haveria possibilidade de enfrentamento da crise, a não ser por intermédio de sua proposta, da confiança incondicional na dinâmica do mercado como reguladora da economia do país. As políticas neoliberais direcionavam as ações dos governantes a seguirem os ditames da globalização do mercado, da desregulamentação, do encolhimento estatal e do reconhecimento da falência dos esquemas compensatórios. Nesse sentido, a busca incessante pela competitividade tornou-se tema de discursos de governantes e parlamentares, na medida em que os rumos da economia mundial impunham como única solução possível para a resolução da crise e o alcance da competitividade, a aplicação das políticas neoliberais. A nãoaceitação e o descumprimento das regras impostas conduziria a nação ao fracasso econômico e ao distanciamento dos países considerados desenvolvidos; ou seja, a não ser que se adotassem na íntegra as propostas neoliberais, se estaria fadado ao fracasso e ao isolamento. 
O neoliberalismo é um projeto político, econômico e social, de caráter hegemônico, que está fundamentado na subordinação absoluta da sociedade ao mercado livre e à não intervenção estatal; destarte, os pilares teóricometodológicos da proposta neoliberal são a desestatização, a desregulamentação e a desuniversalização. $O$ projeto hegemônico neoliberal apresenta o conceito de mercado como o eixo das relações sociais e, portanto, como propulsor da organização social. $\bigcirc$ ideário neoliberal teoriza que o mercado livre é o elemento regulador de toda a sociedade, ou seja, verificase o fetiche do mercado como a panacéia para todos os problemas econômicos e sociais (SHIGUNOV NETO e MACIEL, 2004).

Entretanto, o que se pode verificar após mais de duas décadas de implantação das propostas neoliberais é que os objetivos apregoados por seus ideólogos não vingaram; ao invés disso, verificou-se o inverso: estagnação da economia, formação de grandes monopólios, crescimento acelerado das desigualdades sociais, aumento da miséria e pobreza, aumento do desemprego, aumento dos lucros das empresas, entre outras conseqüências funestas. A implantação das propostas neoliberais implicou em problemas de ordem social: agravamento das desigualdades sociais; exclusão e segmentação social; aumento da pobreza; aumento do desemprego; crescimento da miséria, fome, marginalidade. Verificaram-se problemas de ordem econômica, como: desvio crescente de recursos para a especulação; incapacidade crescente de absorção de mão-de-obra e do trabalho humano; incapacidade de recuperar e sustentar ritmos elevados de crescimento. Portanto, as políticas neoliberais e a reestruturação produtiva alteram de modo significativo a organização da produção, a política de emprego, o mercado de trabalho e os sindicatos.

A sociedade contemporânea, também denominada de sociedade do conhecimento, pautada na ideologia neoliberal, apresenta o conhecimento como o elemento fundamental e gerador de riqueza para as organizações, tendo um papel determinante, apesar de não ser exclusivo.

\section{A importância do conhecimento}

Na realidade, o que se pretende demonstrar com essa breve análise é o papel fundamental que a informação e o conhecimento têm adquirido em nossas vidas, principalmente, nas últimas décadas. Talvez, poder-se-ia supor que tal importância adquirida pela informação e pelo conhecimento deve-se exclusivamente à influência que o modo de produção capitalista exerce na sociedade. Uma sociedade pautada nos princípios capitalistas de divisão do trabalho e da busca incansável do lucro.

O termo conhecimento tem origem do latim cognoscere e pode ser definido, como: o ato ou efeito de conhecer; a idéia, noção; a informação, notícia, ciência; a prática da vida; experiência; o discernimento, critério, apreciação; a consciência de si mesmo; acordo; a pessoa com quem travamos relações; o documento escrito, declaração ou recibo de que consta ter alguém em seu poder certas mercadorias; a nota de despacho de mercadorias entregues para transporte; o recibo de parcela de contribuição direta; o sentido mais amplo, atributo geral que têm os seres vivos de reagir ativamente ao mundo circundante, na medida de sua organização biológica e no sentido de sua sobrevivência; a posição, pelo pensamento, de um objeto como objeto, 
variando o grau de passividade ou de atividade que admitam nessa posição; a apropriação do objeto pelo pensamento, como quer que se conceba essa apropriação; como definição, como percepção clara, apreensão completa, análise. (DICIONÁRIO Aurélio)

O conhecimento, nada mais é do que um processo próprio do ser humano de aprender e vir a conhecer algo que Ihe era estranho, ou seja, é um processo de apreensão do mundo que o rodeia. Pode-se, então, em função de se viver em uma sociedade capitalista, admitir que existem dois tipos de conhecimentos produzidos pela sociedade: os conhecimentos científicos (produzidos, hipoteticamente, para atender as necessidades da sociedade) e os conhecimentos técnicos ou tecnológicos (produzidos para atender as necessidades exclusivas da indústria e dos modos de produção). Portanto, pode-se presumir que ambos os conhecimentos produzidos - os científicos e os tecnológicos, são de grande importância social, econômica e cultural.

Faz-se necessário lembrar que, como normalmente acontece, conhecimento não pode ser confundido com habilidade e aptidão; aquele se refere ao processo de aprendizagem de algo, enquanto que estes se referem aos conhecimentos técnicos, estando correlacionados a alguma profissão.

A construção e o desenvolvimento dos conhecimentos científico e tecnológico implicam, necessariamente, em aquisição e troca de informações. Assim, a construção do conhecimento só é possível com a informação.

termo informação tem origem do latim informatione e significa: ato ou efeito de informar; dados acerca de alguém ou de algo; conhecimento, participação; comunicação ou notícia trazida ao conhecimento de uma pessoa ou do público; instrução, direção; parecer dado em processo, nas repartições públicas; fase inicial do processo de falência; conhecimento amplo e bem fundamentado, resultante de análise e combinação de vários uniformes; processamento de dados; coleção de fatos ou de outros dados fornecidos à máquina, a fim de se objetivar um processamento; segundo a teoria da informação - é a medida da redução da incerteza sobre um determinado estado de coisas, por intermédio de uma mensagem. (DICIONÁRIO Aurélio)

Atualmente, o conhecimento é o principal insumo no processo de produção. Os tradicionais fatores de produção, mão de obra, recursos naturais e capital estão cedendo espaço cada vez maior para a informação e o conhecimento na sua importância para a cadeia produtiva. A importância do conhecimento na economia e na sociedade define o que hoje se conhece como sociedade do conhecimento.

modelo capitalista atualmente vigente exige que as empresas e as organizações que competem por recursos sejam lucrativas, ou seja, tenham uma vantagem de mercado sobre os concorrentes.

Ao se falar de organizações refere-se implicitamente ao conceito de ciência administrativa, que se dedica ao estudo e compreensão do comportamento das organizações.

A FIG. I apresenta a percepção do que se entende como ciência administrativa e sua inter-relação com outras ciências que contribuem para a compreensão dos problemas organizacionais. Nesse sentido, entendese que a administração é a área do conhecimento humano que se preocupa com o estudo das organizações, tanto de seus aspectos internos quanto dos aspectos externos. 


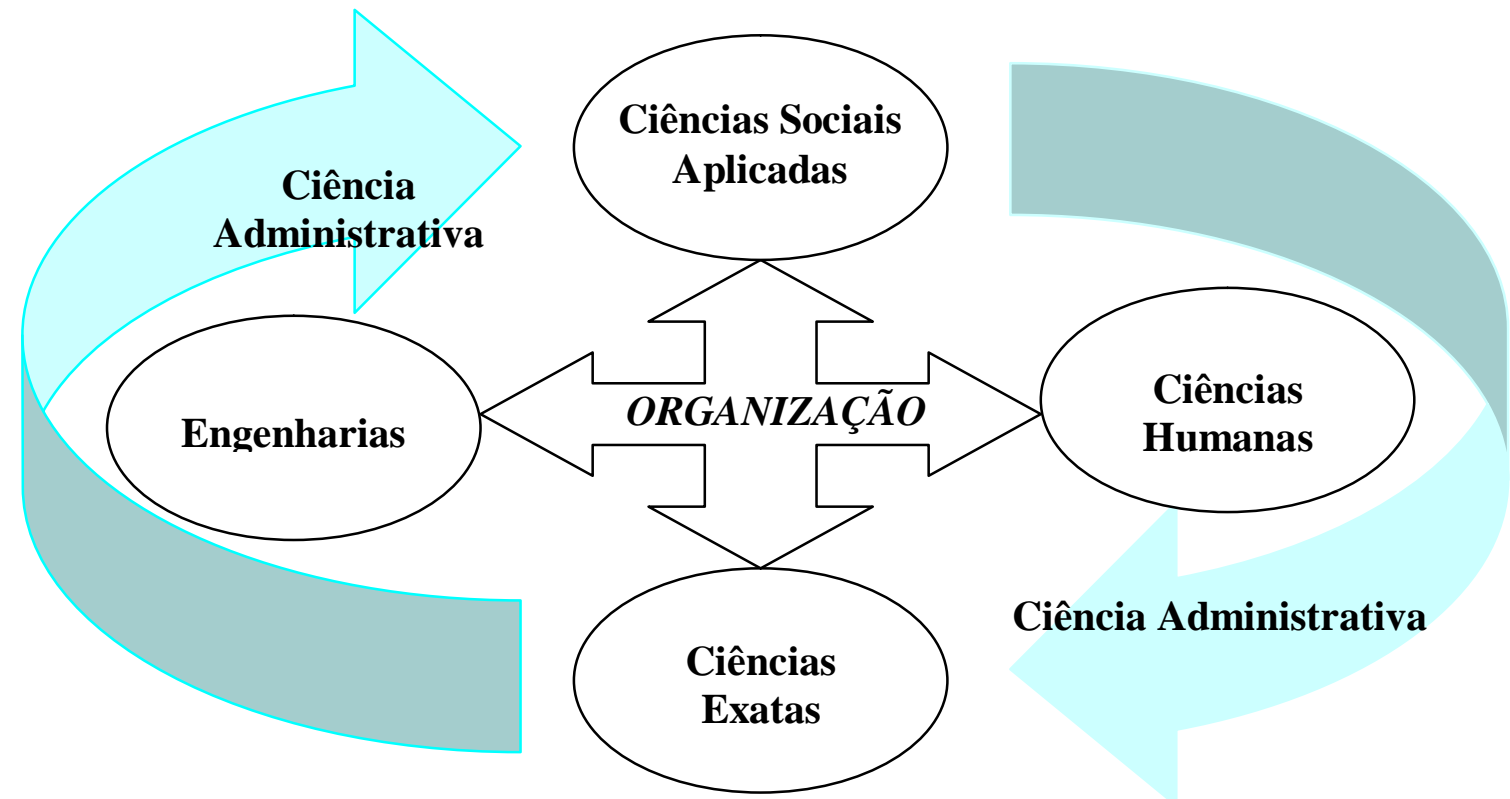

FIGURA I - Conceito de Ciência Administrativa

Fonte: Shigunov Neto, Teixeira e Campos, 2005

A ciência administrativa é constituída pelas abordagens, teorias, práticas e modelos administrativos formulados, testados e implementados ao longo de sua recente história de vida, quase cem anos, que serão completados em 2006.

A ciência administrativa é a sistematização dos conhecimentos humanos produzidos acerca das organizações. Tem, portanto, como objeto de estudo, as organizações. Entretanto, para a compreensão da complexidade organizacional, a administração apropria-se dos conhecimentos gerados por outras ciências e áreas de conhecimento humano. É importante destacar que na ciência administrativa, como em qualquer outra área do conhecimento humano, na maioria das vezes os conhecimentos são (re)produzidos a partir do que já existe (SHIGUNOV NETO; TEIXEIRA; CAMPOS, 2005).

Assim, cabe à ciência administrativa propor teorias e modelos administrativos que utilizem de forma eficaz e eficientemente os recursos materiais, financeiros e, principalmente, o capital humano das organizações em prol dos objetivos organizacionais.

Stewart (1998) destaca que

os ativos físicos de uma empresa baseada no conhecimento contribuem muito menos para o valor de seu produto (ou serviço) final do que os ativos intangíveis - os talentos dos seus funcionários, a eficácia de seus sistemas gerenciais, o caráter de seu relacionamento com os clientes - que, juntos, constituem seu capital intelectual (p. 5I).

Davenport e Prusak (1998) também destacam a importância do conhecimento na empresa afirmando que, numa economia global, o conhecimento pode ser a maior vantagem competitiva da empresa. 
A grande implicação da sociedade do conhecimento nas organizações é que elas têm que se estruturar em função da importância estratégica do conhecimento. Por importância estratégica do conhecimento entende-se que a organização tem que responder adequadamente às demandas do meio ambiente de forma inovadora, fornecendo-lhe produtos, serviços e soluções adequadas ao atendimento das necessidades do meio ambiente competitivo. Como se manifesta esta importância estratégica? Pelo lançamento de produtos e serviços que encantem, não só os consumidores como também os stakeholders da empresa.

\section{Conhecimento tácito e explíito}

A definição de conhecimento amplamente aceita é a de Polanyi (NONAKA e TAKEUCHI, 1997), que o aborda sob dois aspectos: o conhecimento tácito e o conhecimento explícito. O conhecimento explícito é aquele registrado em algum meio externo ao indivíduo, como arquivos magnéticos, sistemas de informação e/ou impresso em papel. $O$ conhecimento tácito é aquele que está na cabeça dos indivíduos e dela somente saem por necessidades contextuais, espontâneas ou dirigidas. "O conhecimento tácito implica em parte de habilidades técnicas - o tipo de destreza informal e de difícil especificação, incorporada ao termo 'know-how'"(NONAKA, 2000, p. 33).

O aproveitamento do conhecimento explícito nas organizações é bem mais fácil, por ser codificado ou, pelo menos codificável e transita de forma relativamente clara nos domínios da organização. $\bigcirc$ problema colocado pelos pesquisadores do conhecimento, como Nonaka e Takeuchi (1997) reside em como transformar o conhecimento tácito em explícito. Notadamente, no aproveitamento deste conhecimento para o sucesso das organizações, num processo conhecido como gestão do conhecimento.

\section{Gestão do conhecimento organizacional}

Conhecimento organizacional é todo o conhecimento tácito detido pelos empregados da organização e pelo conhecimento explícito que circula na empresa. Este conhecimento é, consciente ou inconscientemente, gerido pelos empregados da organização. $\bigcirc$ que se pretende com a gestão do conhecimento? Aproveitar da melhor forma o conhecimento tácito e o conhecimento explícito de uma organização. Nesse sentido, Davenport e Prusak (1998) assinalam que "muitas empresas abordam a geração do conhecimento como uma 'caixa preta', procurando apenas contratar pessoal preparado e depois deixando que se virem por conta própria." (p. 63).

A empresa pode incentivar e não investir indiscriminadamente no conhecimento tácito dos funcionários; há que se ter um critério. Dentre os diversos critérios possíveis, escolheu-se o de core competence, devido ao fato de ser considerado um conceito interno à organização e menos abrangente ou mais específico que os demais, e por relacionar-se diretamente com a vantagem competitiva da empresa. As estratégias podem ser copiadas, mas não os processos. 
conceito de core competence, conforme proposto por Hamel e Prahalad ( 1995) consiste naquele conhecimento (envolvendo experiência, know how) particular da empresa e que determina sua vantagem competitiva do mercado.

Davenport e Prusak (1998) propõem que o conhecimento deva ser alinhado e avaliado segundo a contribuição dos funcionários para a melhoria do nível de conhecimento da empresa. Apresentam como exemplo uma grande empresa de consultoria que reformulou seus sistemas de avaliação de desempenho para incluir contribuições para o banco de conhecimento da firma como fator importante para decisões relativas à remuneração.

\section{A organização e seu meio ambiente}

Sveiby (1998) aborda o relacionamento entre o ambiente onde o indivíduo atua e a organização de uma forma geral (competitivo) e o conhecimento e a competência. Para ele, a competência é determinada pelo ambiente, que determina se a competência é necessária.

Sveiby (1998, p. 43) afirma ainda que, se o indivíduo muda de ambiente, ele perde a competência. Da mesma forma pode-se dizer que se o ambiente muda, o indivíduo perde a competência, já que a competência está diretamente ligada a ele. Decorre daí que o indivíduo tem que ser aproveitado no ambiente para o qual tem competência e que ela deve ser permanentemente atualizada em função das exigências do meio ambiente em que a organização atua. De nada adianta uma core competence se ela não tiver valor de mercado, ou seja, se não determinar uma vantagem competitiva para a empresa.

As competências têm que ser permanentemente avaliadas em função do seu valor para o mercado.

\section{Criação de conhecimento organizacional}

Por criação de conhecimento organizacional entende-se a capacidade de uma empresa criar novo conhecimento, difundi-lo na organização como um todo e incorporá-lo a produtos, serviços e sistemas. (NONAKA e TAKEUCHI, 1997). Com esse propósito, Krogh, Kazuo e Nonaka (200I) sugerem que a criação do conhecimento organizacional seja realizado em cinco fases:

- primeira fase - compartilhamento do conhecimento tácito;

- segunda fase - criação de conceitos;

- terceira fase - justificação dos conceitos;

- quarta fase - construção de protótipos;

- quinta fase - nivelação do conhecimento.

Nesse sentido, faz-se necessário esclarecer que ter um insight ou palpite altamente pessoal tem pouco valor para a empresa, a não ser que o indivíduo possa convertê-lo em conhecimento explícito, permitindo assim que ele seja compartilhado com outros indivíduos na empresa. (NONAKA e TAKEUCHI, 1997, p. II). 


\section{Transformação do conhecimento tácito em explíito}

Em termos de gestão do conhecimento, uma das principais preocupações refere-se a como transformar o conhecimento tácito em proveito da organização (NONAKA e TAKEUCHI, 1997).

O conhecimento tácito dos indivíduos é formado intencionalmente ou contingencialmente. Intencionalmente, através de educação formal, cursos, leituras e interesse próprio do indivíduo em adquirir determinados tipos de conhecimento. Contingencialmente, pela sua participação em trabalhos, determinados pela empresa, em que ele é designado pelo reconhecimento de seu conhecimento ou pela disponibilidade de sua capacidade manifestada pelo cargo que ocupa no momento em que a empresa necessita dele.

Propõe-se aqui transformar o processo de conhecimento tácito de informal e determinado pelo indivíduo, em formal, e incentivado pela organização. Incentivado, já que nenhuma organização pode obrigar o indivíduo a adquirir conhecimentos tácitos e em tornar acessível aos demais componentes de uma organização os conhecimentos tácitos que existem nos indivíduos, de forma que, em se precisando de algum tipo de conhecimento, seja possível encontrar na organização, ou mesmo fora dela, alguém que o possua. Ou seja, gerenciar de forma positiva o processo do conhecimento, segundo depoimento de Garvin, que afirma que empresas como a Honda, Corning e General Electric "gerenciam ativamente o processo de aprendizado para assegurar a sua ocorrência mais por deliberação do que por acaso". (GARVIN, 2000, p. 55).

Segundo a teoria contingencial, o ambiente determina a estrutura da organização. Cury (1994) esclarece que as contingências são formulações específicas de interação entre um comportamento operante de um organismo e seu ambiente, uma relação se-então. A implicação contingencial na organização se refere ao ambiente que exige que ela administre o seu conhecimento de forma a adequar os resultados da empresa segundo as exigências do meio ambiente, ou a usar o seu conhecimento para transformá-lo. Desta forma, o ambiente determina a estrutura de absorção, criação e gerenciamento dos conhecimentos tácitos dos empregados e dos explícitos da organização.

Nonaka (2000) enfatiza o estabelecimento de estruturas formais de criação do conhecimento tácito e sua transformação em conhecimento explícito, quando a

compreensão da criação do conhecimento como processo de explicitação do conhecimento tácito - uma questão de metáforas, analogias e modelos - tem implicações diretas em como a empresa projeta a organização e define os papéis e responsabilidades gerenciais. Esse é o como da empresa criadora de conhecimento, as estruturas e práticas que convertem a visão da empresa em tecnologias e produtos inovadores (p. 4l).

Esta estrutura deve prover meios institucionais para estimular os detentores do conhecimento a explicitá-los segundo a necessidade da organização. Um exemplo disso é descrito por Nonaka (2000) quando afirma 
o elemento central da abordagem japonesa (de criação do conhecimento) é o reconhecimento de que a criação de novos conhecimentos não é uma simples questão de processamento de informações objetivas. Ao contrário, depende do aproveitamento dos insights, das intuições e dos palpites tácitos e muitas vezes altamente subjetivos dos diferentes empregados, de modo a converter essas contribuições em algo sujeito a testes e possibilitar o uso em toda a organização (p. 30).

\section{Critérios para estimulação da criação do conhecimento}

O processo de gestão de conhecimento organizacional deve começar por uma priorização do conhecimento necessário à organização. Klein (1998) adverte que "existem, certamente, alguns aspectos-chave na gestão estratégica dos ativos de conhecimento que indicam se a empresa pode se manter unida face ao conflito entre os diversos interesses dos participantes". (p. 259).

Davenport e Prusak (1998, p. 97) também destacam estes conflitos, relatando uma experiência na realização do mapa de conhecimento de uma empresa de alta tecnologia, quando ela "tentou criar um mapa descrevendo os principais repositórios humanos e técnicos do conhecimento relativo ao desenvolvimento de novos produtos, o projeto quase naufragou vítima de intensas manobras no sentido de estar bem situado no mapa".

Por outro lado Nonaka (2000) destaca a necessidade de um ideal para a criação de conhecimentos afirmando que "A criação de novos conhecimentos envolve tanto ideais quanto idéias" (grifo do autor). Para a minimização de conflitos e para a existência de um ideal, sugerimos a adoção dos conceitos de visão estratégica e de core competence. A visão estratégica supre a necessidade de ideais de longo prazo, o desenvolvimento de inovativas competências, de forma a surpreender tanto os clientes quanto à concorrência. No curto prazo, a minimização de conflitos pode ser realizada determinação da core competence da organização, como critério de priorização de investimentos na área do conhecimento organizacional.

Core competence ou competências essenciais, como já definido, é um conceito proposto por Hamel e Prahalad (1995) que "referem-se a uma classe de benefícios ao cliente". Existem empresas que detêm competências que as distinguem das demais empresas, e citam como exemplos a motorola em termos de minituarização de equipamentos e comunicação sem fio e a Apple em termos de "facilidade de aprender e usar". O conceito de core competence estimula o aperfeiçoamento de uma competência já existente, atendendo cada vez mais adequadamente às necessidades atuais dos seus consumidores. Este é um critério de curto prazo porque são conhecimentos já dominados pela empresa e que têm que ser aperfeiçoados, visando sempre estar à frente dos concorrentes.

Visão estratégica refere-se a um estado ideal da empresa no futuro, que serve como inspiração para as ações diárias e planos de mudança da empresa. No dizer de Tregoe, Zimmermann, Smith e Tobia 
(1993, p. 14) "definimos visão ou estratégia como a estrutura que orienta as escolhas determinantes da natureza e do rumo da organização". Uma das escolhas podem ser os conhecimentos que a organização deve desenvolver para realização desta visão estratégica. A necessidade de uma visão estratégia pode ser avaliada pelo depoimento de Helmut Volkmann, diretor sênior da Siemens, citado por Krogh, Kazuo e Nonaka (200I, p. I8I) "o pessoal da Siemens passa por meu escritório e me pergunta sobre o futuro. Eles estão interessados nas coisas que faço e todos os dias consigo mais apoio na empresa". Este apoio pode ser traduzindo em geração de conhecimento, alinhado com o futuro delineado para a organização.

Por intermédio da definição de suas competências essências e de sua visão estratégica, a organização determinará critérios de estímulo e seleção de conhecimento tanto tácitos como explícitos, dentro de um conceito econômico de eficiência. A eficácia é determinada pelas definições corretas das competências essenciais da empresa e da visão estratégica que dêem à organização vantagem no ambiente competitivo.

○ próximo passo será o de identificar na empresa quem detêm este conhecimento. Isto poderá ser realizado por um sistema de informações, de preferência computadorizado, onde os empregados cadastrarão sua instrução formal, interesses, experiências, desejos de trabalhar em determinados tipos de projetos e de adquirir certos tipos de experiências e conhecimentos. Através deste sistema de informações, os gerentes poderão identificar na organização, através de instrumentos formais de pesquisa e não somente de conhecimento próprio, aqueles indivíduos que poderão contribuir de melhor forma para a realização de um projeto. Esta experiência já existe na HP e na Microsoft, conforme depoimento de Davenport e Prusak (1998), que têm sistemas de informações onde os funcionários disponibilizam informações sobre seus conhecimentos formais e informais, habilidades e experiências. Davenport e Prusak (I998, p. 88) "esclarecem que um mapa do conhecimento seja ele um mapa real, Páginas Amarelas do conhecimento ou um banco de dados sofisticado indica o conhecimento, porém não o contém".

Porém, um sistema de informações é absolutamente passivo. É necessária a atualização do banco de dados e a sua utilização pelos empregados da organização, notadamente os gerentes de projetos. Tais procedimentos podem ser estimulados através de regras e regulamentos, no seu aspecto formal, como também através de reuniões periódicas ou extraordinárias. Com estes instrumentos os gerentes serão motivados a utilizar o melhor conhecimento existente dentro da empresa e avaliados por estas utilizações, enquanto os funcionários serão estimulados e avaliados pela sua contribuição nos projetos. Kami ( 1988 ) propõe medidas de segundas-feiras, quando são avaliados os acontecimentos e resultados da semana anterior e quais os desafios e ameaças não só para a semana corrente como para o futuro da organização, numa avaliação estratégica permanente do meio ambiente empresarial. Nesta análise ritual podem ser também investigados os conhecimentos necessários para o enfrentamento dos novos desafios. 


\section{Considerações finais}

A intervenção na estrutura organizacional e nas práticas administrativas, formalizando a gerência do conhecimento através de atribuições de gerência de conhecimento em cargos gerenciais, regras e procedimentos estimulará o desenvolvimento do conhecimento tácito e sua transformação em conhecimento explícito. Porém, esta gestão deve-se pautar em critérios objetivos que propomos que sejam as competências essenciais e a visão estratégica da empresa. Por meio destas ações a organização construirá uma cultura de valorização do conhecimento portado pelos indivíduos, estimulando o desenvolvimento ainda maior destes conhecimentos e da sua transformação em conhecimento explícito que resultem em produtos organizacionais valorizados pelo mercado e assim determinem a vantagem competitiva da organização e o seu conseqüente sucesso.

\section{Society of the knowledge and administrative science: initial reflections on the organizations management of the knowledge and its implications}

The present article is intended to present some initial reflections on the organizations paper of the management of the knowledge and its implications. In the capitalist society the competitive advantage is determinative for the success, even though for the survival of the organizations, mainly for those with lucrative ends. In this context, the knowledge is if becoming the main factor of production, determinative element of the competitive advantage of the companies. All the competitors have access to the too much factors of production, but what she distinguishes a company of another one is the knowledge that each one they withhold. That one that it obtains to better manage the knowledge of its employees, of form to translate this knowledge in products and services valued for the society of the consumption, will have a competitive advantage. Considering it importance of the knowledge as distinctive factor of production in the company and the necessity of if getting one better exploitation for to accomplish of the strategical objectives of the organizations, this article considers that the knowledge in the organizations is managed of conscientious form and according to its contribution for the essential abilities and/or the strategical vision of the organization. It also presents some instruments that can be used by the company to define these criteria of election and for the stimulaton of the generation of knowledge and the insertion of the management of the knowledge in the organizacional culture.

Key-words: Knowledge; Administrative science; Knowledge society; Organization.

\section{Referências}

CHIAVENATO, Idalberto. Introdução à teoria geral da administração. Rio de Janeiro: Campus, 2000.

CURY, Antonio. Organizações \& Métodos. São Paulo: Atlas, 1994. 
DICIONÁRIO AuréllO. Curitiba, Positivo, 2005.

GARVIN, David A. Construindo a organização que aprende. In: Gestão do Conhecimento. Harvard Business Review. Rio de Janeiro: Campus, 2000. p.50-81.

KAMI, Michael J. Momento de Decisão. São Paulo: McGraw-Hill, 1989.

KLEIN, David A. A gestão estratégica do capital intelectual. Rio de Janeiro: Qualitymark, 1998.

KROGH, Georg von; ICHIJO, Kazuo; NONAKA, Ikujjiro. Facilitando a criação de Conhecimento. Rio de Janeiro: Campus, 2001.

NONAKA, Iküjro; TAKEUCHI, Hirotaka. Criação de Conhecimento na Empresa. 12.ed. Rio de Janeiro: Campus, 1997.

NONAKA, Ikujjiro. A empresa criadora do conhecimento. In: Gestão do Conhecimento. Harvard Business Review. Rio de Janeiro: Campus, 2000. p.27-49.

HAMEL, Gary; PRAHALAND, C.K. Competindo pelo futuro. Rio de Janeiro: Campus, 1995.

TREGOE, Benjamin; ZIMMMERMAN, John W.; SMITH, Ronald A., TOBIA, Peter MI. Visão Empresarial na prática. Rio de Janeiro: Campus, 1993.

SHIGUNOV NETO, Alexandre; MACIEL, Lizete Shizue Bomura. As políticas neoliberais e a formação de professores: propostas de formaçōes simplistas e aligeiradas em épocas de transformaçōes. In: SHIGUNOU NETO, Alexandre; MACLEL, Lizete Shizue Bomura. Formação de professores. passado, presente e futuro. São Paulo: Cortez, 2004.

SHIGuNOU NETO, Alexandre; TEXXEIRA, Alexandre Andrade; CAMPOS, Letícia Mirella Fischer. Fundamentos da Ciência Administrativa. Rio de Janeiro: Ciência Moderna, 2005.

STEWART, Thomas A. Capital intelectual. Rio de Janeiro: Campus, 1998.

SUEIBY, Karl Erik. A nova riqueza das organizações. Rio de Janeiro: Campus, 1998. 